\title{
Expression of trkB in Human Neuroblastoma in Relation to MYCN Expression and Retinoic Acid Treatment
}

\author{
Anders Edsjö, Erik Lavenius, Helén Nilsson, Jeff C. Hoehner, Per Simonsson, \\ Lloyd A. Culp, Tommy Martinsson, Christer Larsson, and Sven Påhlman
}

Department of Laboratory Medicine, Division of Molecular Medicine (AE, EL, HN, JCH, CL, SP), and Clinical Chemistry (PS), Lund University, University Hospital MAS, Malmö, Sweden; Department of Molecular Biology and Microbiology (LAC), Case Western Reserve University, School of Medicine, Cleveland, Ohio; Department of Clinical Genetics (TM), Sahlgrenska University Hospital/East, Gothenburg, Novartis Sweden (EL), Täby, Sweden; and Department of Pediatric Surgery (JCH), Johns Hopkins Hospital, Baltimore, Maryland

\begin{abstract}
SUMMARY: Expression of full-length trkB can be found in some highly malignant neuroblastoma tumors with an amplified $M Y C N$ gene. This contrasts sympathetic neuroblasts, from which neuroblastomas are thought to arise, which neither express trkB nor are dependent on the $\mathrm{p} 145^{\text {trkB }}$ ligands, brain-derived neurotrophic factor (BDNF) or neurotrophin-4/5, for their normal development. In this study we show that trkB was expressed in two out of five neuroblastoma tumors with amplified $M Y C N$, while no trkB expression was observed when the $M Y C N$ gene was overexpressed in a non- $M Y C N$-amplified neuroblastoma cell line. This shows that MYCN overexpression per se is not sufficient to induce trkB expression. trkB expression and BDNF responsiveness in neuroblastoma cells can be induced by all-trans-retinoic acid (RA). When SH-SY5Y cells were stimulated with a combination of RA and BDNF, norepinephrine and tyrosine hydroxylase levels were unaltered, showing that the cells did not change toward a more catecholaminergic sympathetic phenotype. However, expression of growth-associated protein 43, indicative of a neuronal phenotype, was elevated. Vesicular acetylcholine transporter, choline acetyl transferase, and neuropeptide tyrosine mRNA levels also increased in RA-BDNF-treated cells, which could suggest that these cells develop into a sympathetic cholinergic phenotype. In addition, treatment with RA-induced expression of the platelet-derived growth factor receptor- $\alpha$. As previously shown for BDNF, platelet-derived growth factor stimulated growth of the RA-treated cells, findings that could have clinical relevance. If these receptors mediate a mitogenic signal in vivo also, this might limit the effect of RA treatment on neuroblastoma patients. (Lab Invest 2003, 83:813-823).
\end{abstract}

$T$ he childhood malignancy neuroblastoma is derived from cells of the developing sympathetic nervous system. The neuroblastoma cells are arrested at immature stages of sympathetic differentiation, although the stage of tumor cell maturation varies from one tumor to another and often also within a single tumor. This immaturity is frequently manifested in phenotypic characteristics resembling those of sympathetic progenitor cells such as expression of the embryonic and fetal transcription factors dHAND and human achaete-scute homolog-1 (HASH-1) (Gestblom et al, 1997, 1999; Hoehner et al, 1996a; Påhlman and Hedborg, 2000). Such progenitor cells give rise to

DOI: 10.1097/01.LAB.0000074895.48776.D8

Received January 7, 2003.

This work was supported by the Swedish Cancer Society, the Children Cancer Foundation of Sweden, HKH Kronprinsessan Lovisas Förening for Barnasjukvård, Hans von Kantzows Stiftelse, and Malmö University Hospital Research Funds.

Address reprint requests to: Dr. Sven Påhlman, Department of Laboratory Medicine, Division of Molecular Medicine, Lund University, University Hospital MAS, Entrance 78, S-205 02 Malmö, Sweden. E-mail: sven.pablman@molmed.mas.lu.se three major closely related, sympathetic cell lineages: the neuronal/ganglionic, the small intensely fluorescent, and the chromaffin cell lineages (Patterson, 1990). The hormones and growth factors determining rat sympathetic progenitor cell lineage selection are grossly understood and involve glucocorticoids, classical growth factors, and neurotrophins (Anderson, 1993, 1997). For example, development into and along the neuronal lineage requires sequential exposure to insulin-like growth factors, basic fibroblast growth factor, and the neurotrophins nerve growth factor (NGF) and neurotrophin(NT)-3 (DiCicco-Bloom and Black, 1988; Stemple et al, 1988; Verdi and Anderson, 1994; Zackenfels et al, 1995).

In mammals, the neurotrophin family of growth factors consists of NGF, brain-derived neurotrophic factor (BDNF), NT-3, and NT-4 (also known as NT-5) (Barbacid, 1995; Barde, 1994). Their high affinity receptors belong to the trk gene family, encoding tyrosine kinase receptors. Thus, NGF binds $\mathrm{p} 140^{\text {trkA }}$, BDNF, and NT-4 bind $\mathrm{p} 145^{t r k B}$; and NT-3 recognizes $\mathrm{p} 145^{\text {trkC }}$. In addition, there is some cross-talk between the various neurotrophins and their receptors (Barbacid, 1995). Both NT-3 and NGF are involved in the 
late phases of sympathetic neuronal differentiation, and in agreement with this, trkA and trkC are expressed in human sympathetic neuroblasts (Hoehner et al, 1995). Furthermore, mice lacking either NGF, trkA, or NT-3 have a reduced number of sympathetic ganglion cells; the NT-3 effect is apparently being mediated via $140^{\text {trkA }}$, showing explicitly the vital roles of NGF and NT-3 for development and survival of these neurons (Barbacid, 1995). In contrast, expression data indicate that $\operatorname{trk} B$ is not expressed in human sympathetic neurons or neuroblasts (Hoehner et al, 1995); in trkB or BDNF/NT-4-deficient mice, the number of sympathetic neurons appears to be unaffected (Barbacid, 1995). This strongly suggests that neither BDNF nor NT-4 have major roles during normal sympathetic neuronal differentiation. However, trkB is expressed in the chromaffin cells of human paraganglia at fetal stages, suggesting that $\mathrm{p} 145^{\text {trkB }}$ signaling is involved in the development of this sympathetic cell type (Hoehner et al, 1995).

Despite their sympathetic characteristics, neuroblastoma cells can express trkB. Truncated trkB mRNA is found in some differentiated tumors, while full-length trkB mRNA is almost exclusively expressed in MYCN-amplified, highly malignant neuroblastoma tumors (Nakagawara et al, 1994). Furthermore, alltrans-retinoic acid (RA) induces trkB expression in cultured human SH-SY5Y neuroblastoma cells (Kaplan et al, 1993; Matsumoto et al, 1995). The receptors are functional and mediate BDNF-induced morphologic differentiation. Under serum-free growth conditions, the RA-BDNF-treated cells appear to terminally differentiate (Encinas et al, 2000). These findings are difficult to explain in a context of normal sympathetic neuronal differentiation, considering the apparent lack of trkB expression in nonmalignant sympathetic neuroblasts and neurons. One putative explanation could be that the RA-BDNF-treated neuroblastoma cells shift toward a nonsympathetic neuronal or to a sympathetic neuroendocrine (chromaffin) phenotype. Previous studies have shown that RA alone induces morphologic differentiation of SH-SY5Y neuroblastoma cells and induces a small increase in choline actyltransferase activity (Adem et al, 1987; Påhlman et al, 1984), without promoting extensive norepinephrine or epinephrine production, the major transmitters of the sympathetic nervous system. However, the SH-SY5Y cells have the capacity to acquire a more developed noradrenergic phenotype, eg, 12O-tetradecanoyl-phorbol-13-acetate (TPA) induces sympathetic neuronal differentiation in these cells, including a drastic increase in synthesized and stored norepinephrine (Påhlman et al, 1981, 1991). Thus, RA might induce a switch in the differentiation program of the SH-SY5Y cells, which would be in keeping with the well-established capacity of RA to shift cells into specific lineages during normal development.

In this report we have investigated if $M Y C N$ overexpression is causally linked to trkB expression in neuroblastoma cells and found that this is not the case. We have also induced trkB expression by treating SH-SY5Y cells with RA and analyzed the differentiated phenotype of RA-BDNF-treated SH-SY5Y cells. This treatment led to an increased expression of general neuronal marker genes and the cholinergic marker genes vesicular acetylcholine transporter (VAChT) and choline acetyl transferase (ChAT), suggesting an RABDNF-induced phenotypic shift from a sympathetic noradrenergic toward a cholinergic neuronal phenotype of these neuroblastoma cells. We further show that RA induces expression of platelet-derived growth factor receptor- $\alpha$ (PDGFR- $\alpha)$ and that RA-induced growth inhibition could be reversed by stimulation with cognate ligands.

\section{Results}

\section{trkB Expression During Human Fetal Sympathetic Development and in MYCN-Amplified Neuroblastoma Tumors}

The trkA and trkB expression in human fetal abdominal cross-sections (developmental weeks 3 to 24) containing sympathetic ganglia and paraganglia was analyzed immunohistochemically. p145 trkB immunoreactivity was detected solely in sympathetic paraganglia (Fig. 1B), most prominently at the later gestational ages tested (21 to 24 weeks). For comparison, p140 trkA immunoreactivity was analyzed in serial sections. Expression of $\mathrm{p} 140^{\text {trkA }}$ was detected in both sympathetic ganglia and paraganglia (Fig. 1A). The chromaffin cells of the human fetal adrenal medulla, detected by tyrosine hydroxylase expression (Fig. 1C), showed a weak $\mathrm{p} 140^{\text {trkA }}$ and a strong $\mathrm{p} 145^{\text {trkC }}$ staining, whereas only a trace amount of $\mathrm{p} 145^{\text {trkB }}$ immunoreactivity was detected, as exemplified in sections from a 24-week-old fetus (Fig. 1, D to F). In addition, adrenal sympathetic neuroblasts were $\mathrm{p} 140^{\text {trkA }}$ and p145 trkC positive, and p145 trkB negative (not shown, Hoehner et al, 1995). Thus, during the developmental stages investigated, $\mathrm{p} 145^{\text {trkB }}$ immunoreactivity was not detectable in sympathetic neuroblasts, while expression was strong in chromaffin cells of sympathetic paraganglia and weak in adrenal chromaffin cells.

In light of the trkB expression pattern in developing sympathetic cells, the expression of trkB in highly malignant neuroblastoma cells seen both in vitro and in vivo (Kaplan et al, 1993; Nakagawara et al, 1994) is difficult to explain because these tumors are considered to be of sympathetic neuronal origin (Hoehner et al, 1996a). Expression of functional, full-length trkB in neuroblastoma tumor specimens was only detected in tumors with an amplified MYCN gene (Nakagawara et al, 1994), and presumably these tumor cells have a high $M Y C N$ expression. To verify that high $M Y C N$ expression due to $M Y C N$ amplification frequently is seen together with trkB expression and that trkB expression is not abundant in non-MYCN-amplified neuroblastomas, a set of cDNAs derived from tumor specimens was analyzed by semiquantitative PCR for the expression of $M Y C N$ and full-length trkB. As shown in Figure 2, $A$ and $B$, none of the seven tumors lacking an amplified MYCN gene showed detectable trkB expression using RA-treated SH-SY5Y cells as a 

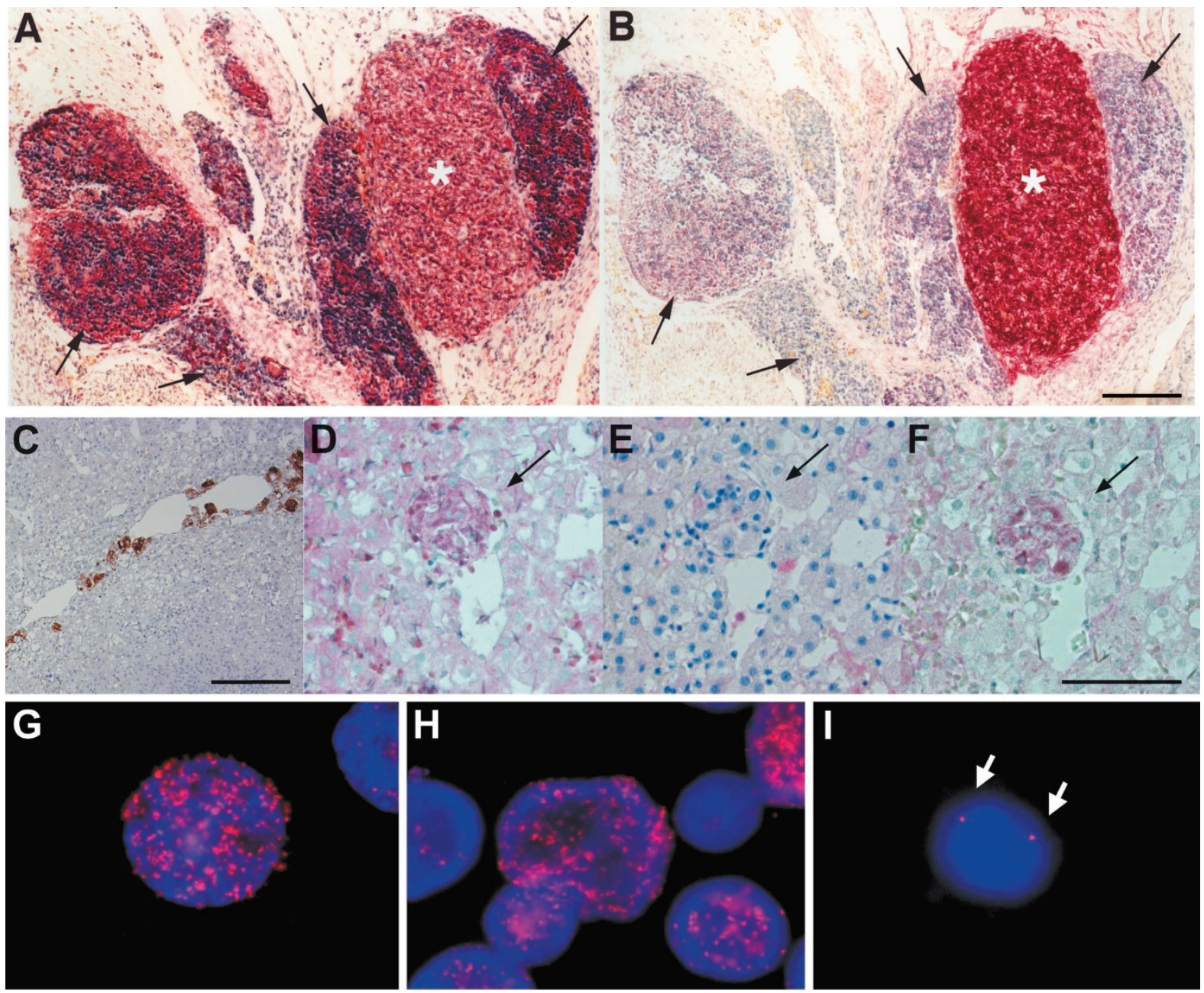

\section{Figure 1.}

Immunohistochemical characterization of $\mathrm{p} 140^{t r k A}(\mathrm{~A}$ and $\mathrm{D}), \mathrm{p} 145^{t r k B}(\mathrm{~B}$ and $\mathrm{E}), \mathrm{p} 145^{t r k C}(\mathrm{~F})$, and tyrosine hydroxylase (TH, C) expression in human fetal sympathetic ganglia, paraganglia, and adrenal chromaffin cells; and MYCN amplification in two neuroblastoma tumors analyzed by fluorescence in situ hybridization (G to I). Abdominal cross-sections of a 16-week developmental age fetus were immunostained for $p 140^{t r k A}(A)$ and $p 145^{t r k B}(B)$, respectively, and counterstained with hematoxylin. The panels show sympathetic ganglia (arrows), immunoreactive for $p 140^{t r k A}$ but not $p 145^{\text {trkB}}$, juxtaposed to a $140^{\text {trkA }}$ and $p 145^{\text {trkB } B}$ positive sympathetic paraganglion (asterisk). Scale bar, $200 \mu \mathrm{m}$. (C to F) Chromaffin cells (arrows) of the adrenal medulla of a 24-week-old human fetus stained for TH (C), p140 trkA (D), $\mathrm{p} 145^{t r k B}(\mathrm{E})$, and $\mathrm{p} 145^{t r k C}(\mathrm{~F})$. Scale bars, $200 \mu \mathrm{M}(\mathrm{C})$ and $100 \mu \mathrm{M}\left(\mathrm{D}\right.$ to F). As seen in D and F, the antibodies directed against $\mathrm{p} 140^{\text {trkA }}$ and $\mathrm{p} 145^{t r k C}$, respectively, gave a slight background staining. (G and H) Cells from MYCN-amplified cases ST130 and ST131, with high number of MYCN gene copies, shown as several red signals in the nucleus. (I) Control cells showing the normal two copies of MYCN (arrows).

positive trkB control. In contrast, two out of five analyzed tumors with an amplified $M Y C N$ gene, determined by either Southern blot (Hedborg et al, 1992) or fluorescence in situ hybridization (FISH) analyses (Fig. 1, $G$ and $H$ ), expressed trkB (Fig. $2 \mathrm{C}$ ), thus confirming previously reported findings (Nakagawara et al, 1994). To test if overexpression of MYCN in non-MYCNamplified neuroblastoma cells is sufficient to induce trkB expression, an $\mathrm{MYCN}$-transfected SK-N-SH cell clone (SKMYC2) and MYCN-amplified neuroblastoma cell lines with high $M Y C N$ expression were analyzed for trkB expression. As shown in Figure 2D, overexpression of $M Y C N$ did not induce trkB expression in SK-N-SH cells, despite the fact that trkB expression can be induced by RA in the SK-N-SH derived sub clone, SH-SY5Y (Kaplan et al, 1993). In addition, RA did not induce MYCN expression in the SH-SY5Y cells (Fig. 2D). Furthermore, trkB was not expressed in any of the tested cell lines with $M Y C N$ amplification (Fig. 2D). The cell line data are in accordance with the findings of Nakagawara et al (Nakagawara et al, 1994), who reported only one out of six tested MYCN amplified cell lines as trkB-positive.

\section{Phenotypic Characterization of RA- and RA-BDNF-treated SH-SY5Y Neuroblastoma Cells}

Previously we reported that RA induces morphologic (neurite growth) and biochemical (neuron-specific enolase) differentiation of SH-SY5Y cells, but RA treatment inhibited the phorbol ester-induced and differentiation-related increase in norepinephrine levels (Påhlman et al, 1984). At a concentration of $1 \mu \mathrm{M}$, RA induced a distinct morphologic differentiation of SH-SY5Y cells characterized by growth coneterminated processes bearing varicosities (Fig. $3 \mathrm{C}$ ). As 
A

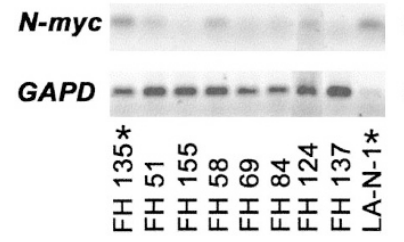

C

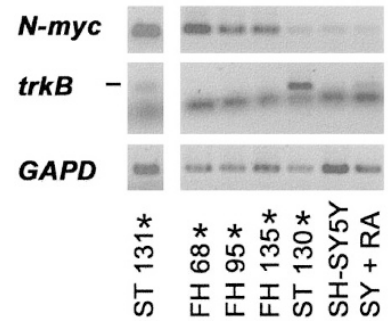

B

trkB -

GAPD

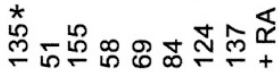

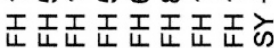

D

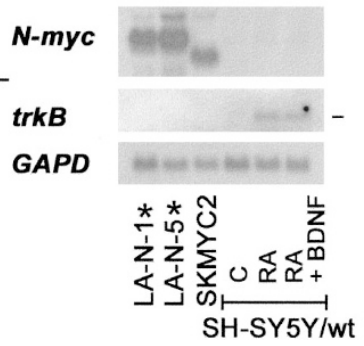

Figure 2.

Expression of MYCN and trkB in neuroblastoma tumors and cell lines. (A) RT-PCR analysis with $M Y C N$-specific PCR primers of tumor samples from one MYCN-amplified (FH135, marked by an asterisk) and seven nonamplified tumors. After 24 PCR cycles, samples were analyzed by agarose gel electrophoresis. In parallel the same quantity of cDNA was amplified for 22 cycles with GAPD-specific primers as a reference for the amount of cDNA in each sample. CDNA from the MYCN-amplified LA-N-1 tumor cell line (asterisk) was included as positive control. (B) RT-PCR analysis with trkB-specific PCR primers of the same tumor samples analyzed in A with SH-SY5Y/wt cells treated for 6 days with $1 \mu \mathrm{m}$ RA as a positive control for trkB expression. After 36 PCR cycles, samples were analyzed. As in A, amplification with GAPDspecific primers for 22 cycles was used as a reference for sample cDNA content. (C) RT-PCR analysis with MYCN- and trkB-specific PCR primers of tumor samples from five MYCN-amplified tumors (asterisks) with CDNA from SH-SY5Y/wt cells ( $\pm 1 \mu \mathrm{M} R$ R) included as a negative and positive control, respectively, for trkB expression. After 26 (MYCM) or 34 (trkB) PCR cycles, samples were analyzed. In parallel the same quantity of cDNA was amplified for 23 cycles (for ST131, 24 cycles) with GAPD-specific primers as a reference for the amount of cDNA in each sample. (D) Northern blot analysis of expression of MYCN (endogenous MYCN $2.7 \mathrm{~kb}$, exogenous MYCN $2.2 \mathrm{~kb}$ ) and trkB (8.2 $\mathrm{kb})$. SH-SY5Y/wt cells were grown for 6 days in serum-containing medium supplemented with $1 \mu \mathrm{M}$ RA or $1 \mu \mathrm{M}$ RA combined with $100 \mathrm{ng} / \mathrm{ml}$ brain-derived neurotrophic factor. Fifteen $\mu \mathrm{g}$ of total RNA was loaded in each lane and GAPD (1.5 kb) mRNA levels were used as a reference for the amount of loaded RNA. Asterisks denote MYCN-amplified cell lines. The bars in B through $D$ indicate the $\operatorname{trk} B$ PCR product and mRNA, respectively.

reported by Kaplan et al (Kaplan et al, 1993), BDNF alone (up to $100 \mathrm{ng} / \mathrm{ml}$ ) did not induce any apparent morphologic changes compared with nontreated controls (Fig. 3, A and B), while RA treatment led to trkB expression and BDNF responsiveness. Compared with the morphology of cells treated with RA only, RA-BDNF-treated cells had a more distinct phenotype, manifested by longer neurites and a considerably higher number of varicosities (Fig. 3, C and D).

As the phenotype of the RA-BDNF-treated cells grown in serum has not been further characterized and the induced trkB expression suggested that these cells did not develop into a noradrenergic, neuronal sympathetic phenotype, we extended the characterization by employing marker genes previously used to phenotypically describe the neuronal and neuroendocrine cells of the developing human sympathetic nervous system (Gestblom et al, 1997, 1999; Hedborg et al, 1995; Hoehner et al, 1996a). The axonal nature of the
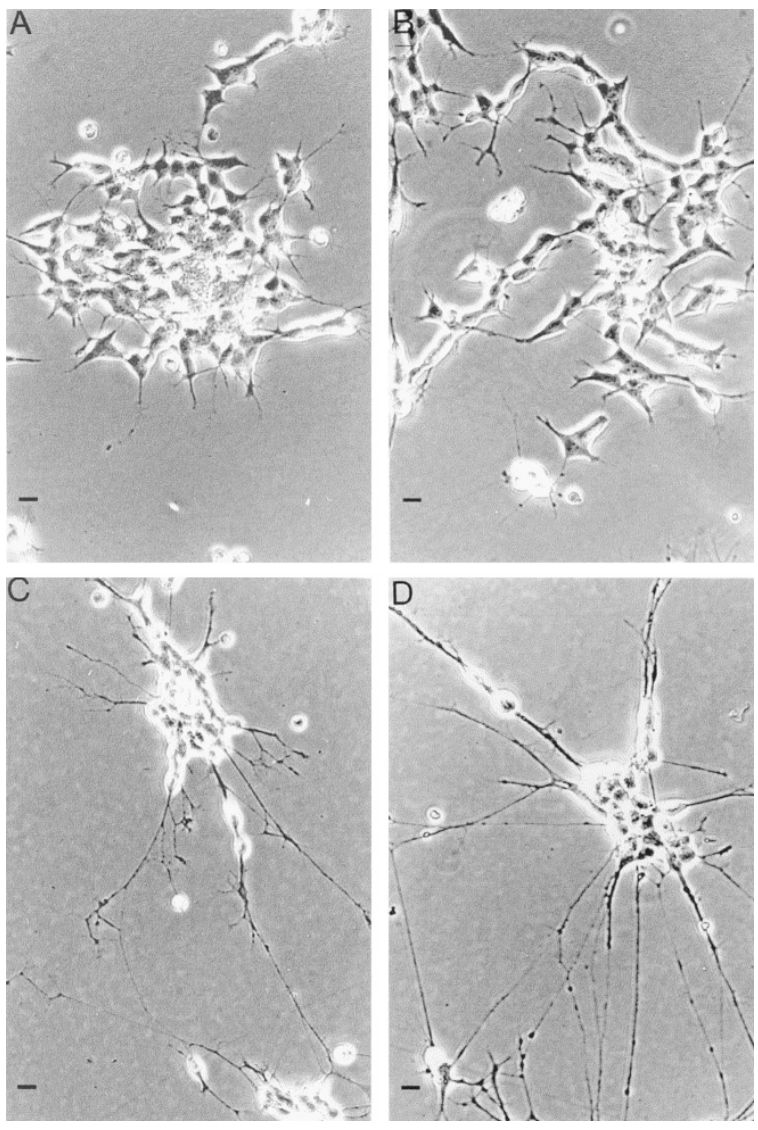

Figure 3.

Morphology of wild-type SH-SY5Y cells cultured in serum-containing medium for 6 days with the following additives: (A) nontreated controls, (B) $100 \mathrm{ng} / \mathrm{ml}$ brain-derived neurotrophic factor (BDNF), (C) $1 \mu \mathrm{M} R A$, and (D) $1 \mu \mathrm{M} R A+$ $100 \mathrm{ng} / \mathrm{ml}$ BDNF. Bars represent $25 \mu \mathrm{m}$.

neurites of both RA- and RA-BDNF-treated cells was corroborated by the increased expression of GAP-43 (Fig. 4), a gene encoding an axonal protein involved in growth cone motility and synapse formation. RA induced less than a 2-fold increase in GAP-43 expression for up to 9 days of treatment. Consistent with previously published results from experiments performed under slightly different conditions (Encinas et al, 1999; Lesser et al, 1997), RA-BDNF treatment resulted in a 5- to 8-fold increase after 6 and 9 days of cell exposure. For comparison, we also included in our analysis SH-SY5Y/trkA cells treated for 4 days with NGF (Fig. 4), a treatment leading to increased GAP-43 expression and neuronal sympathetic differentiation (Edsjö et al, 2001; Lavenius et al, 1995).

\section{Neurotransmitter Synthesis in RA- and RA-BDNF-Treated SH-SY5Y Cells}

Norepinephrine and NPY are two important neurotransmitters produced in catecholaminergic cells of the sympathetic nervous system. The concentration of the major neurotransmitter, norepinephrine, was analyzed in RA- and RA-BDNF-treated cells. No significant increase in norepinephrine levels compared with control cells was detected, but there was a tendency 


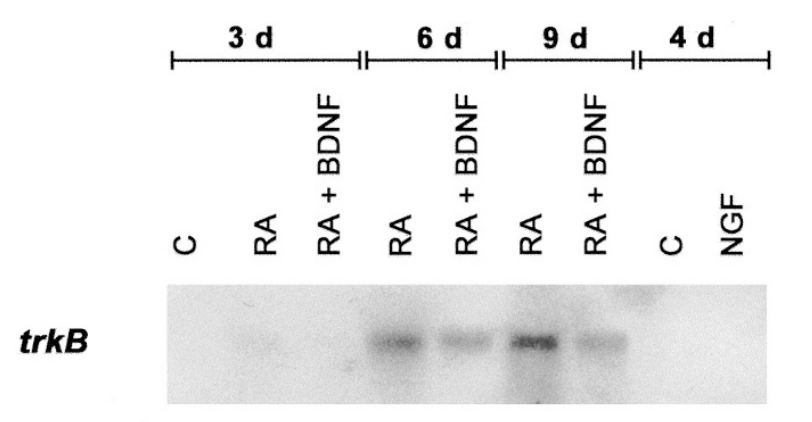

GAP-43

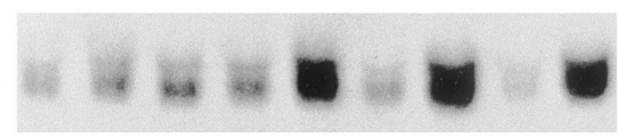

$\begin{array}{lllllllll}\text { Induction: } 1 & 1.8 & 2.6 & 1.8 & 4.7 & 1.8 & 7.6 & 1 & 6.1\end{array}$

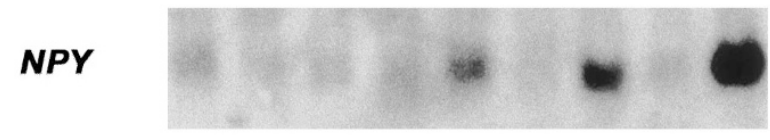

$\begin{array}{lllllllll}\text { Induction: } 1 & 0.6 & 0.5 & 0.7 & 1.6 & 0.4 & 3.8 & 1 & 12.1\end{array}$

GAPD

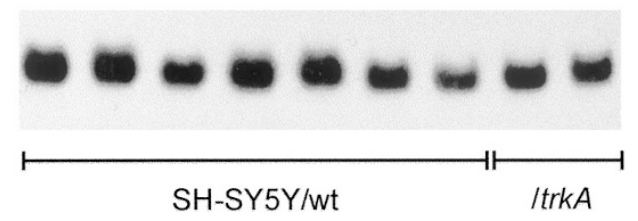

Figure 4.

Northern blot analysis of trkB, GAP-43, and NPY expression in RA and RA-brain-derived neurotrophic factor (BDNF)-treated SH-SY5Y/wt cells and in nerve growth factor-treated SH-SY5Y/trkA cells. Cells were grown in serumcontaining medium, with the addition of $1 \mu \mathrm{m} \mathrm{RA}$ and $1 \mu \mathrm{m} \mathrm{RA}+100 \mathrm{ng} / \mathrm{ml}$ BDNF (SH-SY5Y/wt) or $100 \mathrm{ng} / \mathrm{ml}$ NGF (SH-SY5Y/trkA), for the indicated time periods. Total RNA $(15 \mu \mathrm{g})$ was analyzed for the expression of trkB $(8.2 \mathrm{~kb})$, GAP-43 (1.4 kb), and NPY $(0.8 \mathrm{~kb})$, using GAPD $(1.5 \mathrm{~kb})$ mRNA levels as a measure of the amount of loaded mRNA. The band intensities were analyzed with phosporimaging, and the relative amounts of mRNA (normalized to GAPD levels and controls) are shown. The increase in trkB mRNA levels could not be quantified since no reliable signal was obtained from the control cell RNA.

toward increased norepinephrine levels in the RABDNF-treated cells (Fig. 5A). However, if real, this effect was small compared with the 6-fold increase in the norepinephrine concentration induced by NGF treatment of SH-SY5Y/trkA cells (Fig. 5A). The ratelimiting enzyme of the catecholamine synthesis, tyrosine hydroxylase $(\mathrm{TH})$, was analyzed in these cells at the protein level by Western blotting. Neither RA nor the combination of RA and BDNF induced an increased TH-expression during a time period ( 3 to 6 days) when the cells differentiated morphologically and biochemically (Fig. 5B). Instead a slight reduction in the TH levels was observed after 6 days of RA and RA-BDNF treatment.

The expression of NPY, which in the sympathetic nervous system characteristically is expressed in the neuronal but not in the chromaffin paraganglionic lineage (Gestblom et al, 1997), increased significantly (approximately 4-fold) after 9 days of RA-BDNF exposure (Fig. 4). The NPY mRNA levels were considerably lower after stimulation for shorter time periods, and treatment with RA alone resulted in decreased NPY mRNA levels at all analyzed time points (Fig. 4).
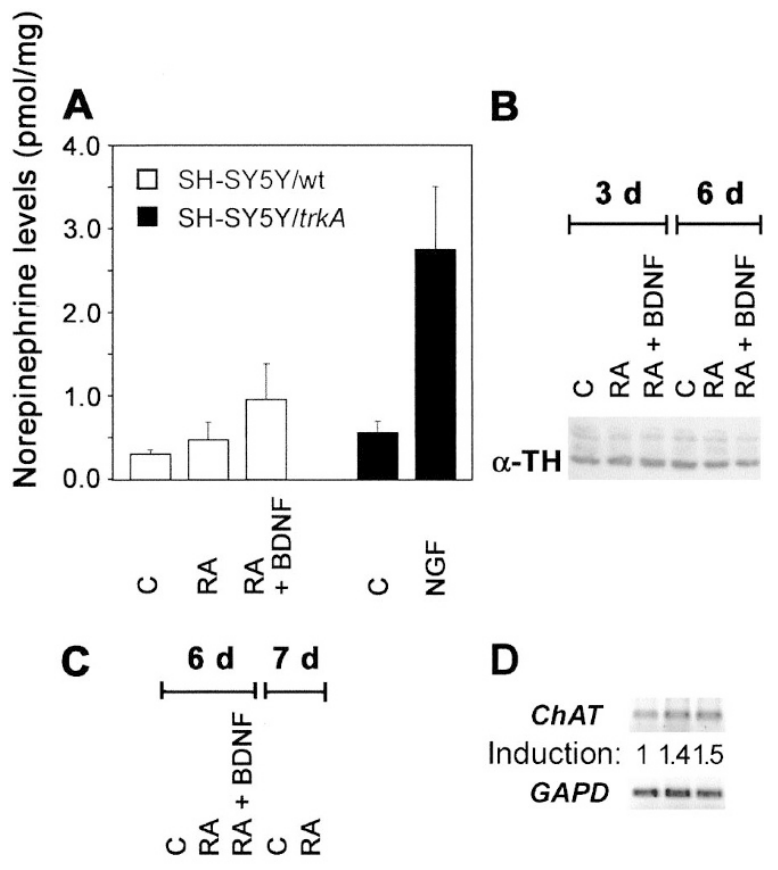

VAChT

Induction: 11.11 .511 .3

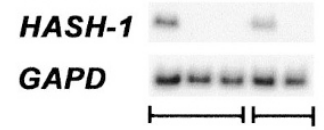

SH-SY5Y/wt LA-N-5

Figure 5.

Phenotypical characterization of RA- and RA-brain-derived neurotrophic factor (BDNF)-treated SH-SY5Y cells. (A) HPLC analysis of norepinephrine levels in cell lysates from SH-SY5Y/wt cells treated for 6 days with $1 \mu \mathrm{m}$ RA or $1 \mu \mathrm{M} \mathrm{RA}+100 \mathrm{ng} / \mathrm{ml} \mathrm{BDNF}(n=5)$ and in SH-SY5Y/trkA-transfected cells treated for 4 days with $100 \mathrm{ng} / \mathrm{ml} \operatorname{NGF}(n=7)$. The mean norepinephrine levels are represented by bars; error bars indicate SEM. (B) Western blot analysis of tyrosine hydroxylase protein levels in RA- and RA-BDNF-treated $\mathrm{SH}-\mathrm{SY} 5 \mathrm{Y} /$ wt cells. Cells were grown in serum-containing medium, with the addition of $1 \mu \mathrm{m}$ RA and $1 \mu \mathrm{m} \mathrm{RA}+100 \mathrm{ng} / \mathrm{ml}$ BDNF. After 3 or 6 days, cells were harvested, and $30 \mu \mathrm{g}$ of whole cell lysate proteins was loaded in each lane. (C) Northern blot analysis of VAChT and HASH-1 expression in RA- and RA-BDNF-treated SH-SY5Y/wt and LA-N-5 cells. Cells were grown in serumcontaining medium, with the addition of $1 \mu \mathrm{M} R A$ or $1 \mu \mathrm{M} R A+100 \mathrm{ng} / \mathrm{ml}$ BDNF, where indicated. After 6 (SH-SY5Y/wt) and 7 days (LA-N-5), cells were harvested and lysed. Fifteen $\mu \mathrm{g}$ of total RNA from each sample was analyzed for the expression of $\operatorname{VAChT}(2.5 \mathrm{~kb})$ and $\mathrm{HASH}-1$ (2.7 kb), using GAPD (1.5 kb) mRNA levels as a measure of the amount of loaded mRNA. The band intensities were analyzed with densitometry, and the relative amounts of mRNA (normalized to GAPD levels and controls) are shown. (D) RT-PCR analysis of samples from SH-SY5Y/wt cells grown as in (C, RA, RA + BDNF), using ChAT-specific primers. After 32 PCR cycles, samples were analyzed. In parallel the same quantity of cDNA was amplified for 19 cycles using GAPD-specific primers and was used as a reference for sample cDNA content.

Although the elevation of NPY expression in cells treated for 9 days with RA-BDNF was significant, it was lower than that seen in TPA-treated SH-SY5Y/wt cells and NGF-treated SH-SY5Y/trkA cells (Fig. 4) and in previous results (Lavenius et al, 1995; Påhlman et al, 1991).

During normal development, a subpopulation of catecholaminergic sympathetic neuroblasts transdifferentiate and become cholinergic. Neuroblastoma cells, as well as catecholaminergic sympathetic neuroblasts, show cholinergic traits with weak expression 
of cholinergic marker genes like ChAT (Biedler et al, 1978; Francis and Landis, 1999; Yokomori et al, 1983). We have previously reported that RA treatment of SH-SY5Y cells promotes a cholinergic phenotype measured as an increase in choline acetyltransferase activity (Adem et al, 1987). A switch to a cholinergic phenotype was recently reported to occur during RA treatment of human NB69 and LA-N-5 neuroblastoma cells (Hill and Robertson, 1997; Handler et al, 2000). We, therefore, analyzed the effect of BDNF on RAtreated SH-SY5Y cells on the expression of the cholinergic marker genes, the acetylcholine transporter VAChT and ChAT. As shown in Figure 5C, RA induced a minute increase in VAChT expression, which was enhanced (1.5-fold over control) by BDNF. The latter increase was in parity with that seen in RA-treated LA-N-5 cells (1.3-fold increase) used as a positive control of neuroblastoma cells acquiring a cholinergic phenotype (Hill and Robertson, 1997). As expected, ChAT expression was also induced by RA and RABDNF (Fig. 5D). The induced cholinergic features of the RA and RA-BDNF-treated SH-SY5Y cells were also accompanied by a complete down-regulation of HASH-1 (Fig. 5C), a transiently expressed transcription factor essential for the commitment and differentiation of migrating neural crest cells toward a noradrenergic sympathetic neuroblastic phenotype.

\section{PDGF Receptor Expression in RA- and RA-BDNF-Treated SH-SY5Y Cells}

The RA-treated SH-SY5Y cells expressing trkB are highly proliferating in the presence of BDNF and serum, and the BDNF stimulation also enhances a migratory response (Matsumoto et al, 1995). Thus, the BDNF-induced differentiation does not lead to growth inhibition, as opposed to for instance the TPA-induced differentiation of SH-SY5Y cells (Påhlman et al, 1991). The development of the phorbolester-driven phenotype requires serum or a growth factor such as PDGF. The receptor, PDGFR- $\alpha$, is expressed in $\mathrm{SH}-\mathrm{SY} 5 \mathrm{Y}$ cells and transduces a mitogenic response upon stimulation with PDGF-AA (Påhlman et al, 1992). As this receptor is down-regulated in TPA-differentiated $\mathrm{SH}$ SY5Y cells, presumably as part of an induced sympathetic differentiation program (Figure 6A; previous results [Påhlman et al, 1992]), we analyzed the expression pattern of this receptor in RA and RA-BDNFtreated cells. RA induced a several-fold increase in PDGFR- $\alpha$ expression, and the combination with BDNF slightly reduced that increase. In contrast, both NGFtreated SH-SY5Y/trkA and TPA-treated SH-SY5Y wild-type cells down-regulated PDGFR- $\alpha$ (Fig. 6A). Thus, with regard to PDGFR- $\alpha$ expression, there was a distinct difference between RA-treated and TPAtreated SH-SY5Y cells.

RA induces differentiation accompanied by growth inhibition in many neuroblastoma cell lines, which is the rationale behind treatment of minimal residual disease in neuroblastoma. It was therefore of interest to test whether PDGF-AA (binds exclusively to the PDGFR- $\alpha$ ) and PDGF-BB (binds both PDGFR- $\alpha$ and
A
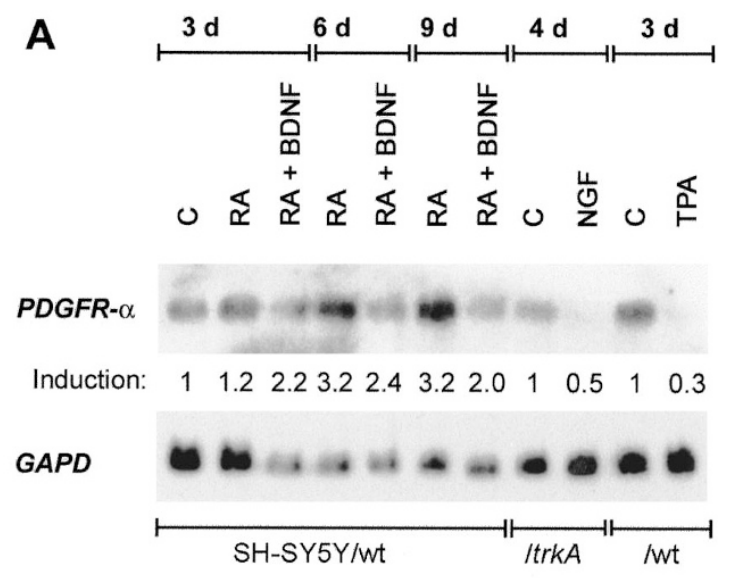

B

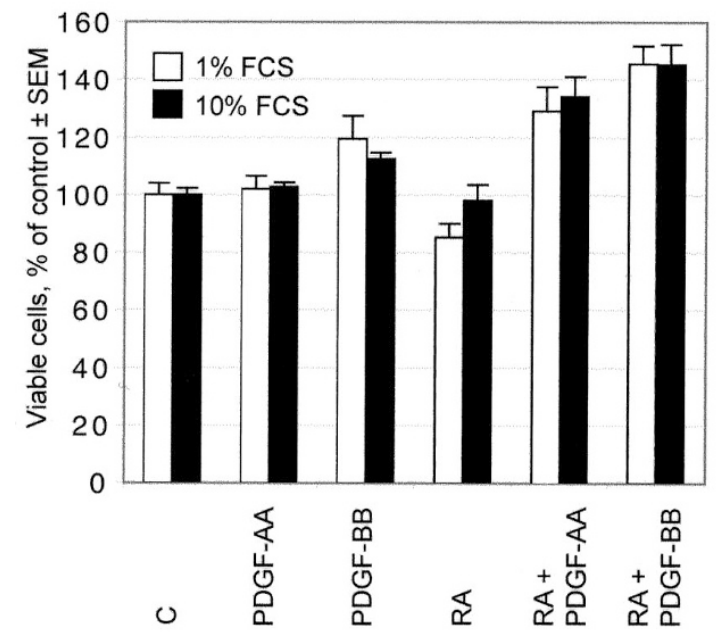

C

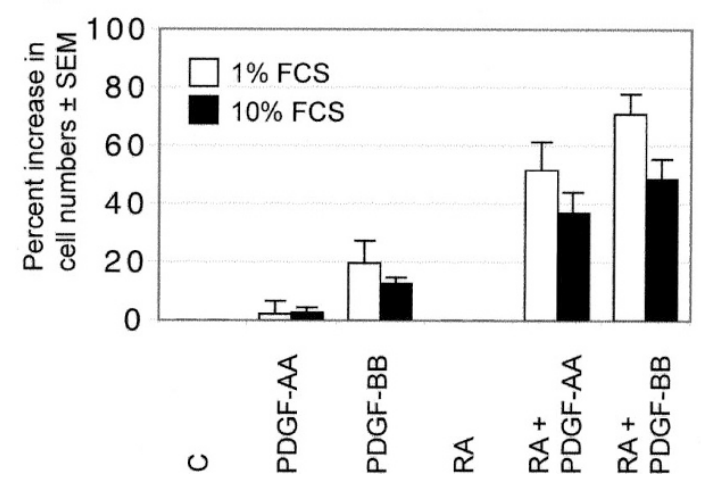

Figure 6.

Platelet-derived growth factor receptor (PDGFR) expression and PDGF effects on cell numbers. (A) Northern blot analysis of PDGFR- $\alpha$ expression in SH-SY5Y/wt cells treated with $1 \mu \mathrm{m}$ RA, $1 \mu \mathrm{m} \mathrm{RA}+100 \mathrm{ng} / \mathrm{ml}$ brain-derived neurotrophic factor and $16 \mathrm{~nm}$ TPA, and in SH-SY5Y/trkA cells treated with 100 $\mathrm{ng} / \mathrm{ml}$ NGF. The cells were harvested after the indicated treatment periods, and $15 \mu \mathrm{g}$ of total RNA was analyzed for the expression of PDGFR- $\alpha(6.5 \mathrm{~kb})$, using GAPD (1.5 kb) mRNA levels as a measure of the amount of loaded mRNA. The band intensities were analyzed with phosporimaging, and the relative amounts of mRNA (normalized to GAPD levels and controls) are shown. (B) Number of viable cells in SH-SY5Y/wt cell cultures, grown for 3 days in $1 \%$ or $10 \%$ FCS, as measured by MTT assay ( $n=8$ to 12). Where indicated, $50 \mathrm{ng} / \mathrm{ml}$ PDGF-AA, $50 \mathrm{ng} / \mathrm{ml} \mathrm{PDGF-BB}$, and/or $1 \mu \mathrm{m}$ RA was added to the medium. (C) Isolated effect of PDGFs \pm RA. Data from 6B, expressed as percent increase in cell numbers in cultures treated with PDGF-AA or -BB \pm $R A$, compared with the amount of viable cells in untreated control and RA-treated cells, respectively. 
PDGFR- $\beta$ ) could mitogenically stimulate the RAtreated SH-SY5Y cells. In the absence of RA, SHSY5Y cell growth was virtually unaffected by PDGF-AA treatment but increased slightly with PDGF-BB (Fig. 6, B and C). In contrast but in agreement with PDGFR- $\alpha$ expression data, PDGF-AA potently stimulated cell growth of RA-treated SH-SY5Y cells, both at $1 \%$ and $10 \%$ serum concentration. PDGF-BB, on the other hand, stimulated growth also in non-RA-treated cells, an effect markedly potentiated in RA-treated cells. Considering the significant effect of PDGF-AA on these cells, the augmented PDGF-BB response was conceivably due to PDGF-BB stimulation of the up-regulated PDGFR- $\alpha$ (Fig. 6, B and C).

\section{Discussion}

Data from characterization of neuroblastoma tumors employing a broad panel of neuronal and neuroendocrine marker genes are consistent with neuroblastomas arising from cells of the sympathetic nervous system (Hoehner et al, 1996a). There are, however, examples of genes expressed in neuroblastoma that usually are not transcribed in developing or mature sympathetic cells. Many of these genes are expressed in other neural crest derived lineages, and one hypothesis is that the expression of such genes reflects the immature or stem cell character of these neuroblastoma cells (Påhlman and Hedborg, 2000). The expression of trkB in some tumors and in RA-treated cultured neuroblastoma cells is one example in which the expression profile does not appear to easily fit into such a developmental model. Although trkB is expressed in developing chromaffin cells of the paraganglia, the differentiation markers of RA-BDNF-treated SH-SY5Y cells are not in keeping with a paraganglionic phenotype. The formation of long neurites, and the GAP-43 induction in RA-BDNF-treated cells, indicate that this treatment promotes a neuronal phenotype (Gestblom et al, 1997). Furthermore, the low norepinephrine levels and lack of $\mathrm{TH}$ induction also argue against these cells becoming chromaffin because high catecholamine production is a hallmark of a chromaffin cell. The phenomenon as such, ie, transdifferentiation of neuroblastoma cells displaying sympathetic neuronal features into a sympathetic extraadrenal chromaffin lineage, can occur spontaneously, preferentially in low-stage neuroblastoma tumors (Gestblom et al, 1997). Instead, RA-BDNF induced the expression of cholinergic marker genes; the increase in VAChT expression appeared primarily to be a BDNF effect, while the increased ChAT expression was mainly RA-induced. These changes, together with the increase in NPY expression, might suggest that the RA-BDNF-treated SH-SY5Y cells develop into a sympathetic cholinergic neuronal lineage, although it is to our knowledge not known if human sympathetic cholinergic neuroblasts or neurons express trkB.

There are now several examples of cultured neuroblastoma cells that respond to RA treatment by expressing cholinergic features (Handler et al, 2000; Hill and Robertson, 1997), suggesting that this is a general effect of RA on neuroblastoma cells. Consistent with this conclusion, cultured sympathetic neuroblasts also switch from a catecholaminergic to a cholinergic phenotype when treated with RA (Matsushima and Bogenmann, 1993). As discussed below, the in vitro RA-induced tumor cell phenotype, including expression of functional growth factor receptors, might in vivo result in tumors with new growth properties potentially adding to an increased malignant behavior; however, we do not know if the induced trkB and $P D G F R-\alpha$ expression is linked to the cholinergic phenotype. To our knowledge, there is only one report in which the clinical behavior of catecholaminergic and cholinergic neuroblastomas has been compared (Yokomori et al, 1983). Based on pretreatment measurements, no clear difference in outcome between catecholaminergic and cholinergic tumors was found in this report. However, in relapsed tumors treated with chemotherapy or radiation, there was a tendency toward a change from a catecholaminergic to a cholinergic phenotype, which might suggest that the cholinergic phenotype is associated with aggressive tumor behavior (Yokomori et al, 1983).

Highly malignant neuroblastomas, including established cell lines, have many characteristics (eg, $\mathrm{HASH}-1$ and $M Y C N$ expression) in common with the sympathoadrenal progenitor cell defined primarily in rodents. Neuroblastoma cells might thus be arrested at such an early differentiation stage that they can behave as progenitor cells. If this is indeed the case, it is reasonable to assume that conditions can be found at which cultured neuroblastoma cells can be forced into cell lineages other than those of the sympathetic nervous system. The neural crest-derived progenitor cells giving rise to the sympathetic nervous system are also progenitors for some of the neurons of the enteric nervous system (Blaugrund et al, 1996; Carnahan et al, 1991). Interestingly, enteric neurons do express trkB (Hoehner et al, 1996b) and NPY (Gaetano et al, 1991; Gordon-Weeks, 1988). Furthermore, although mature intrinsic enteric neurons appear not to express norepinephrine or epinephrine, immature enteric neurons do (Kapur, 1993). Thus, as many of the characteristics of the RA-BDNF-treated cells appear to be similar to those of immature or differentiating enteric neurons, differentiation into this lineage is, formally, an alternative explanation of our data.

Amplification of $M Y C N$ in neuroblastomas correlates strongly to poor prognosis. MYCN functions as a heterodimeric transcription factor, forming a complex with Max. It is generally believed that overexpression of $M Y C N$ in neuroblastoma results in altered gene expression, although few target genes have been identified (Lasorella et al, 2000; Schwab, 2000; Shohet et al, 2002). One question we wanted to answer was whether high MYCN expression was directly linked to the trkB expression observed in some neuroblastomas. We conclude that the trkB expression detected in neuroblastoma tumors is not directed by high MYCN expression. It is a fact, though, that expression of full-length trkB in neuroblastoma specimens primar- 
ily is found in tumors with $M Y C N$ amplification. Whether the trkB expression is regulated via coamplified genes like DDX1 (George et al, 1997; Godbout and Squire, 1993) or merely is a reflection of a phenotypic heterogeneity among neuroblastoma tumors, possibly requiring high $M Y C N$ expression, needs to be further addressed.

The fact that RA induces trkB and PDGFR- $\alpha$ expression in SH-SY5Y cells and that these receptors transduce mitogenic signals to these cells are findings that might have clinical relevance. RA and RA homologues have for a long time been recognized as promising drugs for treatment of neuroblastoma, with the anticipation that they will induce tumor cell differentiation and growth arrest in vivo, similar to the effects seen in vitro. With one noticeable and promising recent exception (Matthay et al, 1999), RA and its homologues have not lived up to these expectations, and RA treatment has, so far, not dramatically changed the outcome of neuroblastoma patients. One molecular explanation for a weak in vivo effect of RA on neuroblastoma growth could be that this treatment induces growth factor receptor expression, similar to the in vitro results presented in this study. If that is the case, these growth factor receptors could transduce mitogenic signals, counteracting the growth inhibitory effect that would follow from the RA-induced differentiation. A future treatment strategy might therefore be to combine RA with one or several of the novel receptor tyrosine kinase inhibitors now becoming available.

\section{Materials and Methods}

\section{Cell Cultures, Tumor Materials, and Assessment of Cell Numbers}

SH-SY5Y wild-type (SH-SY5Y/wt) neuroblastoma cells, a neuroblastic subclone of the non-MYCNamplified SK-N-SH cell line (Biedler et al, 1973), as well as stably trkA-transfected $\mathrm{SH}-\mathrm{SY} 5 \mathrm{Y}$ cells (SHSY5Y/trkA, clone 6:2) (Lavenius et al, 1995), were cultured in Eagle's minimum essential medium with the following additives: 10\% FCS (FCS), $100 \mathrm{lU} / \mathrm{ml}$ penicillin $\mathrm{V}$, and $100 \mu \mathrm{g} / \mathrm{ml}$ streptomycin. LA-N-1, LA-N-2, and LA-N-5 cells were grown in RPMI 1640 medium with $10 \%$ FCS and the same antibiotics added. To induce differentiation the following additives were used: RA (Sigma, St. Louis, Missouri), human recombinant BDNF (PeproTech EC Ltd., London, United Kingdom), mouse NGF 2.5S (Promega, Madison, Wisconsin), and PDGF-AA and -BB (PeproTech). Media, FCS, and antibiotics were from Life Technologies Inc. (Rockville, Maryland). The SKMYC2 clones of SK-N-SH cells transfected with MYCN has previously been described (Judware and Culp, 1995). The RNA analyzed was extracted from cells grown with $200 \mu \mathrm{g} / \mathrm{ml}$ of Hygromycin B (Calbiochem, San Diego, California). The amount of viable cells in cell cultures was analyzed measuring the conversion of the tetrazolium salt MTT to formazan (CellTiter 96, Promega). Cells were plated at a density of 7500 cells/well in 96-well plates with factors used added prior to the addition of cells.
The tumor material used has been described previously (Hedborg et al, 1992; Martinsson et al, 1995). MYCN amplification was determined by either Southern blot (Hedborg et al, 1992; Martinsson et al, 1995) or FISH analyses (Martinsson et al, 1995). FISH analysis was performed as previously described (Fröstad et al, 1999).

\section{Northern Blot and Semiquantitative RT-PCR Analyses}

The guanidine-isothiocyanate/phenol-chloroform extraction method (Chomczynski and Sacchi, 1987) was used for isolation of total cellular RNA. Fifteen $\mu \mathrm{g}$ of RNA was electrophoretically separated on a $1 \%$ agarose-formaldehyde gel and blotted onto a nylon membrane (Hybond-N, Amersham Pharmacia Biotech, Uppsala, Sweden). The following cDNA probes were labeled with $\left[{ }^{32} \mathrm{P}\right]$ dCTP using an oligonucleotide labeling kit (Amersham Pharmacia Biotech): Neuropeptide tyrosine (NPY) (Minth et al, 1986), MYCN (Kohl et al, 1983), glyceraldehyde-3-phosphatedehydrogenase (GAPD) (Tso et al, 1985), growthassociated protein 43 (GAP-43) (Örtoft et al, 1993), trkA (Martin-Zanca et al, 1989), trkB (Klein et al, 1989), VAChT (a 1605 bp probe amplified from LA-N-2 cDNA, using the 30-mer 5'-CGC GGA TCC ATG GAA TCC GCG GAA CCT GCG-3' as forward and the 29-mer 5'-CGC GAA TTC TAG CTG CGG GTG TAG TAG TA-3' as reverse primer), and human PDGFR- $\alpha$ (Claesson-Welsh et al, 1989). Hybridizing probes were visualized by autoradiography, and RNA levels were quantified and related to the corresponding GAPD mRNA level by phosphor image analysis, using a Fuji BAS 2000 equipment (Fujifilm, Tokyo, Japan) or by densitometric analysis.

Total RNA from snap-frozen tumor specimens and cultured cells were extracted as described above and treated with RNase-free DNase I (Appligene Oncor, Illkirch, France) prior to cDNA synthesis. cDNA synthesis was performed using the Gibco BRL SuperScript First-Strand Synthesis System for RT-PCR (Life Technologies Inc.). Duplicates of each sample were made and the reverse transcriptase was added to one of them $(R T+)$, while the other $(R T-)$ was used as a negative control for contaminating genomic DNA in the samples. The cDNA was purified using the QIAquick PCR Purification kit (Quiagen, Venlo, the Netherlands).

In the subsequent $\mathrm{PCR}$ reactions, template cDNAs were mixed with $10 \times$ PCR buffer (Sigma) and $20 \mathrm{~nm}$ of each primer in a total volume of $60 \mu$ l along with $2.5 \mathrm{U}$ of TaqDNA polymerase (Sigma). Amplification was carried out for 19 to 36 cycles, with a denaturation temperature of $95^{\circ} \mathrm{C}$, annealing temperature of $57^{\circ} \mathrm{C}$, and an extension temperature of $72^{\circ} \mathrm{C}$ for 30 seconds each. RT - samples were run in parallel for at least as many cycles as the RT+ samples to check for genomic DNA. Ten $\mu$ l of the collected aliquots were loaded on a $1 \%$ agarose gel stained with SYBR Green I Nucleic Acid Gel Stain (Roche, Basel, Switzerland). Band intensities were recorded and analyzed using LAS-1000 CCD imaging equipment with accompany- 
ing image analyzing software (Fujifilm). For each primer set, the exponential phase of amplification was determined by removing aliquots at four different cycle numbers. The genes analyzed were ChAT (forward primer: 5'-CTGCTGCTATGGTCCTGTGG-3', reverse: 5'-TCAAGGTTGGTGTCCCTGGC -3'); GAPD (forward primer: 5'CCATCACCATCTTCCAGGAGC-3', reverse: 5'-AGTGATGGCATGGACTGTGGTC-3'); MYCN (forward primer: 5'-TTCCTCCTCCAACACCAAGG-3', reverse: 5'-CGCCTCGCTCTTTATCTTCT-3'); and trkB (forward primer: 5'-GAG CAT CAT GTA CAG GAA AT-3', reverse: 5'-CTT GAT GTT CTT CCT CAT GT-3'). The trkB primers will generate a 235-bp PCR product covering a part of the 3 ' end-coding for the tyrosine kinase domain, thereby only amplifying trkB cDNA generated from full-length transcripts and not the cDNAs from the two known truncated trkB mRNAs (Barbacid, 1994; Klein et al, 1989, 1990; Middlemas et al, 1991).

\section{Immunohistochemical and Western Blot Analyses}

Human fetal tissue was obtained from either elective or spontaneous abortions from 9- to 25-weeks gestational age, kindly provided by Dr. B. Sandstedt, Stockholm. Ethical approval (Dnr 93-216) was obtained from the local ethical committee of Karolinska Hospital, Stockholm, Sweden. p140 trkA, $\mathrm{p} 145^{\text {trkB }}$, and p145 trkC expression were analyzed immunocytochemically as described (Hoehner et al, 1995), in which the specificities of the antisera employed (Santa Cruz, CA) were characterized and reported. Sections were counter-stained with hematoxylin.

For Western blot analysis, cells were lysed in $10 \mathrm{~mm}$ Tris- $\mathrm{HCl}$ (pH 7.2), $160 \mathrm{~mm} \mathrm{NaCl}, 1 \%$ Triton X-100, 1\% sodium deoxycholate, $0.1 \%$ SDS, $1 \mathrm{~mm}$ EGTA, $1 \mathrm{~mm}$ EDTA in the presence of Complete Protease Inhibitor (Roche). For TH-protein-expression analysis, $30 \mu \mathrm{g}$ of whole-cell lysate protein was separated on an SDSPAGE gel and blotted onto a Hybond C extra membrane (Amersham Pharmacia Biotech). A monoclonal antityrosine hydroxylase antibody (Roche), diluted 1:500, was used along with a horseradish peroxidase coupled secondary antibody diluted 1:5000 (Amersham Pharmacia Biotech).

\section{Norepinephrine Analysis}

RA and neurotrophin-treated cells $\left(10^{6} / 10-\mathrm{cm}\right.$ plate) were grown for 4 days and then washed and harvested in ice-cold PBS. The pelleted cells were resuspended in $0.5 \mathrm{M}$ trichloroacetic acid and then centrifuged at $21,000 \times g$ for 5 minutes in $4^{\circ} \mathrm{C}$. The supernatant was saved and $\mathrm{pH}$ adjusted to $\mathrm{pH} 4$ with $\mathrm{NaOH}$. The pellet was resuspended in $1 \mathrm{M} \mathrm{NaOH}$ for protein determination according to Bradford. After addition of an internal standard (3,4-dihydroxynorepinephrine) the supernatant samples were extracted and derivatized with 1,2 diphenylethylenediamine as previously described (van der Hoorn et al, 1989). The samples were analyzed by HPLC using a $25 \times 2-\mathrm{mm}$ precolumn (Perisorb RP 18, 30- to 40- $\mu \mathrm{m}$ particle diameter) and a $250 \times 4.6-\mathrm{mm}$ column (Hypersil ODS,
5- $\mu \mathrm{m}$ particle diameter) using $50 \mathrm{~mm} \mathrm{Na}$ acetate $(\mathrm{pH}$ 7.0):acetonitrile:methanol (5:4:1) as mobile phase. The fluorescence was detected with either a Shimadzu RF-10A XL or a Jasco Fluorescence Detector 821, and the signal was integrated with a Shimadzu C-R3A integrator.

\section{Acknowledgement}

We thank Carolin Jönsson for technical assistance.

\section{References}

Adem A, Mattsson ME, Nordberg A, and Påhlman S (1987). Muscarinic receptors in human SH-SY5Y neuroblastoma cell line: Regulation by phorbol ester and retinoic acid-induced differentiation. Brain Res 430:235-242.

Anderson DJ (1993). Molecular control of cell fate in the neural crest: The sympathoadrenal lineage. Annu Rev Neurosci 16:129-158.

Anderson DJ (1997). Cellular and molecular biology of neural crest cell lineage determination. Trends Genet 13:276-280.

Barbacid M (1994). The Trk family of neurotrophin receptors. J Neurobiol 25:1386-1403.

Barbacid M (1995). Neurotrophic factors and their receptors. Curr Opin Cell Biol 7:148-155.

Barde YA (1994). Neurotrophic factors: An evolutionary perspective. J Neurobiol 25:1329-1333.

Biedler JL, Helson L, and Spengler BA (1973). Morphology and growth, tumorigenicity, and cytogenetics of human neuroblastoma cells in continuous culture. Cancer Res 33:26432652.

Biedler JL, Roffler-Tarlov S, Schachner M, and Freedman LS (1978). Multiple neurotransmitter synthesis by human neuroblastoma cell lines and clones. Cancer Res 38:3751-3757.

Blaugrund E, Pham TD, Tennyson VM, Lo L, Sommer L, Anderson DJ, and Gershon MD (1996). Distinct subpopulations of enteric neuronal progenitors defined by time of development, sympathoadrenal lineage markers and Mash1-dependence. Development 122:309-320.

Carnahan JF, Anderson DJ, and Patterson PH (1991). Evidence that enteric neurons may derive from the sympathoadrenal lineage. Dev Biol 148:552-561.

Chomczynski P and Sacchi N (1987). Single-step method of RNA isolation by acid guanidinium thiocyanate- phenolchloroform extraction. Anal Biochem 162:156-159.

Claesson-Welsh L, Eriksson A, Westermark B, and Heldin $\mathrm{CH}$ (1989). cDNA cloning and expression of the human A-type platelet-derived growth factor (PDGF) receptor establishes structural similarity to the B-type PDGF receptor. Proc Natl Acad Sci USA 86:4917-4921.

DiCicco-Bloom E and Black IB (1988). Insulin growth factors regulate the mitotic cycle in cultured rat sympathetic neuroblasts. Proc Natl Acad Sci USA 85:4066-4070.

Edsjö A, Hallberg B, Fagerström S, Larsson C, Axelson H, and Påhlman $S$ (2001). Differences in early and late responses between neurotrophin-stimulated trkA- and trkCtransfected SH-SY5Y neuroblastoma cells. Cell Growth Differ 12:39-50. 
Encinas M, Iglesias M, Liu Y, Wang H, Muhaisen A, Cena V, Gallego C, and Comella JX (2000). Sequential treatment of SH-SY5Y cells with retinoic acid and brain-derived neurotrophic factor gives rise to fully differentiated, neurotrophic factor-dependent, human neuron-like cells. J Neurochem 75:991-1003.

Encinas M, Iglesias M, Llecha N, and Comella JX (1999). Extracellular-regulated kinases and phosphatidylinositol 3-kinase are involved in brain-derived neurotrophic factormediated survival and neuritogenesis of the neuroblastoma cell line SH-SY5Y. J Neurochem 73:1409-1421.

Francis NJ and Landis SC (1999). Cellular and molecular determinants of sympathetic neuron development. Annu Rev Neurosci 22:541-566.

Fröstad B, Martinsson T, Tani E, Falkmer U, Darnfors C, Skoog L, and Kogner P (1999). The use of fine-needle aspiration cytology in the molecular characterization of neuroblastoma in children. Cancer 87:60-68.

Gaetano C, Matsumoto K, and Thiele CJ (1991). Retinoic acid resistant neuroblastoma cells and the expression of insulinlike growth factor-II. Prog Clin Biol Res 366:165-172.

George RE, Kenyon R, McGuckin AG, Kohl N, Kogner P, Christiansen H, Pearson AD, and Lunec J (1997). Analysis of candidate gene co-amplification with MYCN in neuroblastoma. Eur J Cancer 33:2037-2042.

Gestblom C, Grynfeld A, Øra I, Örtoft E, Larsson C, Axelson H, Sandstedt B, Cserjesi P, Olson EN, and Påhlman S (1999). The basic helix-loop-helix transcription factor dHAND, a marker gene for the developing human sympathetic nervous system, is expressed in both high- and low-stage neuroblastomas. Lab Invest 79:67-79.

Gestblom C, Hoehner JC, Hedborg F, Sandstedt B, and Påhlman S (1997). In vivo spontaneous neuronal to neuroendocrine lineage conversion in a subset of neuroblastomas. Am J Pathol 150:107-117.

Godbout R and Squire J (1993). Amplification of a DEAD box protein gene in retinoblastoma cell lines. Proc Natl Acad Sci USA 90:7578-7582.

Gordon-Weeks PR (1988). The ultrastructure of noradrenergic and cholinergic neurons in the autonomic nervous system. In: Björklund A, Hökfelt T, and Owman C, editors. Handbook of chemical neuroanatomy. Amsterdam: Elsevier, $117-181$.

Handler A, Lobo MD, Alonso FJ, Paino CL, and Mena MA (2000). Functional implications of the noradrenergiccholinergic switch induced by retinoic acid in NB69 neuroblastoma cells. J Neurosci Res 60:311-320.

Hedborg F, Lindgren PG, Johansson I, Kogner P, Samuelsson BO, Bekassy AN, Olsen L, Kreuger A, and Påhlman S (1992). N-myc gene amplification in neuroblastoma: A clinical approach using ultrasound guided cutting needle biopsies collected at diagnosis. Med Pediatr Oncol 20:292-300.

Hedborg F, Ohlsson R, Sandstedt B, Grimelius L, Hoehner JC, and Påhlman S (1995). IGF2 expression is a marker for paraganglionic/SIF cell differentiation in neuroblastoma. Am J Pathol 146:833-847.

Hill DP and Robertson KA (1997). Characterization of the cholinergic neuronal differentiation of the human neuroblastoma cell line LA-N-5 after treatment with retinoic acid. Brain Res Dev Brain Res 102:53-67.
Hoehner JC, Gestblom C, Hedborg F, Sandstedt B, Olsen L, and Påhlman S (1996a). A developmental model of neuroblastoma: Differentiating stroma-poor tumors' progress along an extra-adrenal chromaffin lineage. Lab Invest 75 : $659-675$.

Hoehner JC, Olsen L, Sandstedt B, Kaplan DR, and Påhlman $S$ (1995). Association of neurotrophin receptor expression and differentiation in human neuroblastoma. Am J Pathol 147:102-113.

Hoehner JC, Wester T, Påhlman S, and Olsen L (1996b). Localization of neurotrophins and their high-affinity receptors during human enteric nervous system development. Gastroenterology 110:756-767.

Judware R and Culp LA (1995). Over-expression of transfected N-myc oncogene in human SKNSH neuroblastoma cells down-regulates expression of beta 1 integrin subunit. Oncogene 11:2599-2607.

Kaplan DR, Matsumoto K, Lucarelli E, and Thiele CJ (1993). Induction of TrkB by retinoic acid mediates biologic responsiveness to BDNF and differentiation of human neuroblastoma cells. Eukaryotic Signal Transduction Group Neuron 11:321-331.

Kapur RP (1993). Contemporary approaches toward understanding the pathogenesis of Hirschsprung disease [published erratum appears in Pediatr Pathol. 1993;13:270]. Pediatr Pathol 13:83-100.

Klein R, Conway D, Parada LF, and Barbacid M (1990). The trkB tyrosine protein kinase gene codes for a second neurogenic receptor that lacks the catalytic kinase domain. Cell 61:647-656.

Klein R, Parada LF, Coulier F, and Barbacid M (1989). trkB, A novel tyrosine protein kinase receptor expressed during mouse neural development. Embo J 8:3701-3709.

Kohl NE, Kanda N, Schreck RR, Bruns G, Latt SA, Gilbert F, and Alt FW (1983). Transposition and amplification of oncogene-related sequences in human neuroblastomas. Cell 35:359-367.

Lasorella A, Noseda M, Beyna M, and lavarone A (2000). Id2 is a retinoblastoma protein target and mediates signalling by Myc oncoproteins. Nature 407:592-598.

Lavenius E, Gestblom C, Johansson I, Nånberg E, and Påhlman S (1995). Transfection of TRK-A into human neuroblastoma cells restores their ability to differentiate in response to nerve growth factor. Cell Growth Differ 6:727-736.

Lesser SS, Sherwood NT, and Lo DC (1997). Neurotrophins differentially regulate voltage-gated ion channels. Mol Cell Neurosci 10:173-183.

Martin-Zanca D, Oskam R, Mitra G, Copeland T, and Barbacid M (1989). Molecular and biochemical characterization of the human trk proto-oncogene. Mol Cell Biol 9:24-33.

Martinsson T, Sjöberg RM, Hedborg F, and Kogner P (1995). Deletion of chromosome $1 \mathrm{p}$ loci and microsatellite instability in neuroblastomas analyzed with short-tandem repeat polymorphisms. Cancer Res 55:5681-5686.

Matsumoto K, Wada RK, Yamashiro JM, Kaplan DR, and Thiele CJ (1995). Expression of brain-derived neurotrophic factor and p145TrkB affects survival, differentiation, and invasiveness of human neuroblastoma cells. Cancer Res $55: 1798-1806$. 
Matsushima $\mathrm{H}$ and Bogenmann $\mathrm{E}$ (1993). Expression of trkA cDNA in neuroblastomas mediates differentiation in vitro and in vivo. Mol Cell Biol 13:7447-7456.

Matthay KK, Villablanca JG, Seeger RC, Stram DO, Harris RE, Ramsay NK, Swift P, Shimada H, Black CT, Brodeur GM, Gerbing RB, and Reynolds CP (1999). Treatment of high-risk neuroblastoma with intensive chemotherapy, radiotherapy, autologous bone marrow transplantation, and 13-cis- retinoic acid. Children's Cancer Group. N Engl J Med 341:11651173.

Middlemas DS, Lindberg RA, and Hunter T (1991). trkB, A neural receptor protein-tyrosine kinase: Evidence for a fulllength and two truncated receptors. Mol Cell Biol 11:143153.

Minth CD, Andrews PC, and Dixon JE (1986). Characterization, sequence, and expression of the cloned human neuropeptide Y gene. J Biol Chem 261:11974-11979.

Nakagawara A, Azar CG, Scavarda NJ, and Brodeur GM (1994). Expression and function of TRK-B and BDNF in human neuroblastomas. Mol Cell Biol 14:759-767.

Örtoft E, Påhlman S, Andersson G, Parrow V, Betsholtz C, and Hammerling U (1993). Human GAP-43 expression: Multiple start sites for initiation of transcription in differentiating human neuroblastoma cells. Mol Cell Neurosci 4:549-561.

Påhlman S and Hedborg F (2000). Development of the neural crest and sympathetic nervous system. In: Påhlman $S$ and Hedborg F, editors. Amsterdam: Elsevier Science B. V., 9-19.

Påhlman S, Johansson I, Westermark B, and Nister M (1992). Platelet-derived growth factor potentiates phorbol esterinduced neuronal differentiation of human neuroblastoma cells. Cell Growth Differ 3:783-790.

Påhlman S, Meyerson G, Lindgren E, Schalling M, and Johansson I (1991). Insulin-like growth factor I shifts from promoting cell division to potentiating maturation during neuronal differentiation. Proc Natl Acad Sci USA 88:99949998.

Påhlman S, Odelstad L, Larsson E, Grotte G, and Nilsson K (1981). Phenotypic changes of human neuroblastoma cells in culture induced by 12-O-tetradecanoyl-phorbol-13-acetate. Int J Cancer 28:583-589.
Påhlman S, Ruusala Al, Abrahamsson L, Mattsson ME, and Esscher T (1984). Retinoic acid-induced differentiation of cultured human neuroblastoma cells: A comparison with phorbolester-induced differentiation. Cell Differ 14:135-144.

Patterson PH (1990). Control of cell fate in a vertebrate neurogenic lineage. Cell 62:1035-1038.

Schwab M (2000). MYCN amplification in neuroblastoma. In: Schwab M, editor. Amsterdam: Elsevier Science B. V., 7583.

Shohet JM, Hicks MJ, Plon SE, Burlingame SM, Stuart S, Chen SY, Brenner MK, and Nuchtern JG (2002). Minichromosome maintenance protein MCM7 is a direct target of the MYCN transcription factor in neuroblastoma. Cancer Res 62:1123-1128.

Stemple DL, Mahanthappa NK, and Anderson DJ (1988). Basic FGF induces neuronal differentiation, cell division, and NGF dependence in chromaffin cells: A sequence of events in sympathetic development. Neuron 1:517-525.

Tso JY, Sun XH, Kao TH, Reece KS, and Wu R (1985). Isolation and characterization of rat and human glyceraldehyde-3- phosphate dehydrogenase cDNAs: Genomic complexity and molecular evolution of the gene. Nucleic Acids Res 13:2485-2502.

van der Hoorn FA, Boomsma F, Man in 't Veld AJ, and Schalekamp MA (1989). Determination of catecholamines in human plasma by high-performance liquid chromatography: Comparison between a new method with fluorescence detection and an established method with electrochemical detection. J Chromatogr 487:17-28.

Verdi JM and Anderson DJ (1994). Neurotrophins regulate sequential changes in neurotrophin receptor expression by sympathetic neuroblasts. Neuron 13:1359-1372.

Yokomori K, Tsuchida Y, and Saito S (1983). Tyrosine hydroxylase and choline acetyltransferase activity in human neuroblastoma: Correlations with clinical features. Cancer 52:263-272.

Zackenfels K, Oppenheim RW, and Rohrer H (1995). Evidence for an important role of IGF-I and IGF-II for the early development of chick sympathetic neurons. Neuron 14:731741. 